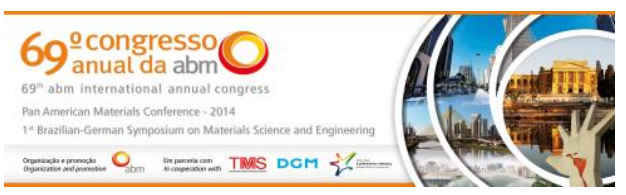

Tema: Metalurgia física e comportamento de materiais em temperaturas elevadas

\title{
ANÁLISE DA INFLUÊNCIA DA COMPOSIÇÃO QUÍMICA NA TRANSFERÊNCIA DE CALOR DURANTE A SOLIDIFICAÇÃO DE AÇOS ESPECIAIS*
}

\author{
Bruna Brito Freitas ${ }^{1}$ \\ Wagner Viana Bielefeldt ${ }^{2}$
}

\section{Resumo}

O lingotamento contínuo de tarugos é um processo extremamente complexo dependente de uma série de variáveis. Todas essas influenciam diretamente na qualidade do aço lingotado e na produtividade, quase sempre de maneira conflituosa. Para compreender o efeito dos parâmetros de processo, é necessário conhecê-los melhor e avaliar sua influência naquilo que é a base do lingotamento contínuo: a transferência de calor na interface metal/molde. Neste estudo foram levantados dados de temperatura durante o lingotamento de diversas corridas de aços em uma planta de aços longos especiais. As medidas de temperatura das paredes do molde da máquina LC foram obtidas, utilizando-se termopares estrategicamente posicionados ao longo do comprimento do molde e nas suas faces. Através da obtenção dos valores de temperatura desses termopares e do levantamento dos dados de processo de cada corrida monitorada, foi possível correlacionar o efeito da composição química com a transferência de calor na interface metal/molde. Por fim, os resultados mostram que aumentando o carbono equivalente observa-se um aumento na transferência de calor.

Palavras-chave: Lingotamento contínuo; Gap; Transferência de calor; Composição química.

\section{INFLUENCE OF CHEMICAL COMPOSITION ON HEAT TRANSFER DURING SOLIDIFICATION OF SPECIAL STEEL}

\section{Abstract}

The continuous casting of billets is a highly complex process that depends on a large number of variables. Those variables directly influence steel quality and productivity in a manner that is often controversial. Greater knowledge of the process parameters is needed in order to better understand their effects on the basis of continuous casting: metal/mold interfacial heat transfer. Temperature data were obtained during several steel heat castings in a special steel plant. The temperature of the mold walls was measured using thermocouples strategically positioned along the length of the mold and its faces. The temperatures and process data of the heats were used to correlate the influence of chemical composition with heat transfer in metal/mold interface. Finally, the results show that raising the carbon equivalent produces an increase in heat transfer.

Keywords: Continuous casting; Gap; Heat transfer; Chemical composition.

1 Eng. Metalúrgico, Programa de Pós-Graduação em Engenharia de Minas, Metalúrgica e de Materiais, UFRGS, Porto Alegre, RS, Brasil.

2 Eng. Metalúrgico, Professor Doutor, PPGE3M, UFRGS, Porto Alegre, RS, Brasil.

* Contribuição técnica ao 69 Congresso Anual da ABM - Internacional e ao 14ํㅡㄹ ENET - Encontro Nacional de Estudantes de Engenharia Metalúrgica, de Materiais e de Minas, 21 a 25 de julho de 2014, São Paulo, SP, Brasil. 


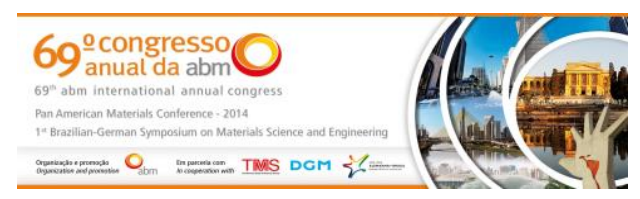

\section{INTRODUÇÃO}

No atual estágio de desenvolvimento da sociedade, é impossível imaginar o mundo sem o uso do aço. A produção de aço é um forte indicador do estágio de desenvolvimento econômico de um país. Seu consumo cresce proporcionalmente à construção de edifícios, instalação de meios de comunicação e produção de equipamentos. Esses materiais já se tornaram corriqueiros no cotidiano, mas fabricá-los exige aciarias com altos níveis de desempenho. O foco principal é a qualidade dos produtos. Uma área de influência decisiva nesse quesito é o lingotamento contínuo.

A função básica de um sistema de lingotamento contínuo é converter o aço líquido de uma dada composição química em uma peça sólida, com uma determinada forma e tamanho, através de uma série de operações [1]. Dependendo da geometria, o produto do lingotamento contínuo pode ser um tarugo, um bloco, uma placa ou ainda um perfil.

A solidificação do aço durante o lingotamento é obtida em três etapas distintas, que governam a solidificação do metal. A primeira etapa ocorre pelo contato do aço líquido com o molde de cobre resfriado a água, chamada zona de resfriamento primário ou região do molde [2,3]. Esta etapa é determinante para a qualidade superficial e a produtividade, pois é onde forma-se a casca sólida inicial. É importante na produtividade porque o molde deve solidificar uma casca sólida espessa o suficiente para suportar o metal líquido do interior do veio [1]. Da mesma forma, para manter qualidade superficial é crucial ter controle perante a região do menisco [4]. Quanto mais rápida for a solidificação, mais rápida pode ser a velocidade de lingotamento, aumentando a produtividade. Para analisar a transferência de calor metal/molde é necessário entender os diversos parâmetros que podem influenciar este processo. A própria composição química [1-5] da corrida é uma variável importante. Em uma planta de aços especiais, que pode trabalhar com centenas de qualidades, essa variável deve ser considerada.

$\mathrm{Na}$ segunda etapa do lingotamento, realiza-se o borrifamento de água ou mistura de água e ar sobre a superfície de um lingote já com uma casca solidificada, no chamado resfriamento secundário, ou região dos chuveiros [6,7].

A terceira e última etapa ocorre com resfriamento pelo ar na chamada região de radiação livre. O principal fenômeno envolvido no processo de lingotamento contínuo é a transferência de calor, que ocorre nessas três etapas.

Qualquer massa que esteja a uma temperatura diferente do seu entorno realiza trocas térmicas a fim de alcançar o equilíbrio térmico. Esse fenômeno é explicado pela lei zero da termodinâmica. A segunda lei da termodinâmica explica que a propagação de calor é a transição de energia térmica que ocorre da maior para a menor temperatura. A energia térmica pode passar de um corpo para outro fundamentalmente por: condução, convecção e radiação. A transferência de calor que ocorre na superfície do tarugo é chamada de transferência Newtoniana de calor, sendo essa uma combinação das três formas citadas acima [8]. A atuação desses mecanismos de transferência de calor durante o processo de solidificação no molde do lingotamento contínuo e o perfil de temperaturas são apresentados na figura 1. Os mecanismos de transferência de calor são representados através das temperaturas mostradas na figura 1. É possível notar uma queda de temperatura acentuada na região entre o molde e a casca sólida, possivelmente devido à formação de um gap de ar.

* Contribuição técnica ao 69ํ Congresso Anual da ABM - Internacional e ao 14ํㅡㄹ ENEMET - Encontro Nacional de Estudantes de Engenharia Metalúrgica, de Materiais e de Minas, 21 a 25 de julho de 2014, São Paulo, SP, Brasil. 


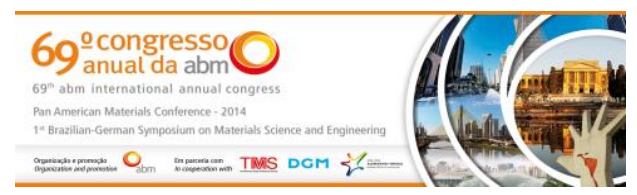

O objetivo desse trabalho é avaliar a transferência de calor devido às mudanças na composição química. Uma forma de quantificar esses dados é através da instrumentação do molde.

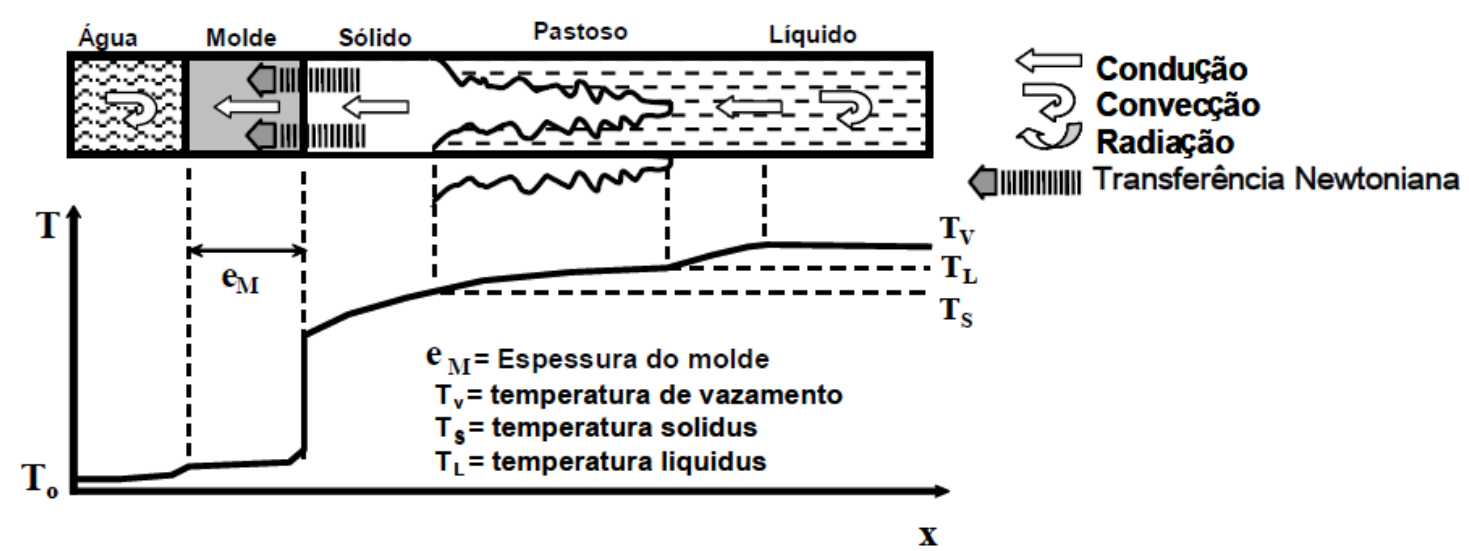

Figura 1. Mecanismos de transferência de calor no sistema metal/molde [9].

\section{MATERIAIS E MÉTODOS}

Para as avaliações das corridas foram analisados parâmetros de uma planta de lingotamento contínuo de aços especiais. Cada corrida possuía em torno de 65 toneladas, tendo o distribuidor capacidade para 15t e a máquina de lingotamento operando com 3 veios. O sistema tem uma altura de aproximadamente 10 metros, medidos do solo até onde está o distribuidor. O raio da máquina é de 9 metros e a distância linear até o início do oxicorte é de 24 metros. O veio 3 foi instrumentado com termopares fixos no molde e pirômetros fixos e móveis na região dos chuveiros e de radiação livre, respectivamente, para análise da transferência de calor de 362 corridas. Dessas corridas, foram avaliadas três, com variações no carbono equivalente.

\subsection{Molde}

Foi utilizado um molde com seção 155 x 155mm que apresenta variações ao longo de seu comprimento. Além disso, os cantos possuem um raio de adoçamento, reduzindo as tensões de solidificação, por exemplo, minimizando o aparecimento de trincas off-corner. Para obtenção dos dados de temperatura, o mesmo foi instrumentado com 42 termopares distribuídos nos raios interno, externo e face lateral.

Os parâmetros termofísicos do molde foram obtidos via manuais técnicos do fabricante. A peça é fabricada de cobre e possui um revestimento interno constituído de uma camada depositada de cromo de aproximadamente $1 \mathrm{~mm}$, utilizada para melhorar a resistência ao desgaste do interior do molde.

São realizadas medições periódicas das dimensões internas do molde, analisando distorções geométricas que podem levar a formação de defeitos e desgastes causados principalmente pela introdução da barra falsa na parte inferior do molde. Segundo o fabricante, temperaturas acima de $350^{\circ} \mathrm{C}$ podem alterar as características do molde.

* Contribuição técnica ao 69 Congresso Anual da ABM - Internacional e ao 14ํㅡㄹ ENET - Encontro Nacional de Estudantes de Engenharia Metalúrgica, de Materiais e de Minas, 21 a 25 de julho de 2014, São Paulo, SP, Brasil. 


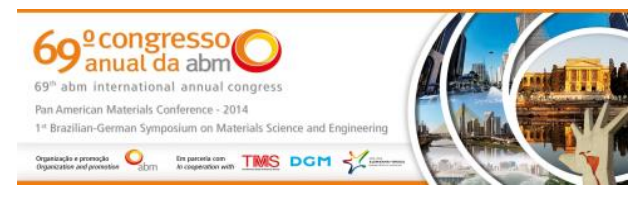

\subsection{Instrumentação com Termopares}

Conforme citado anteriormente o molde foi instrumentados com 42 termopares, do tipo $\mathrm{K}$, distribuídos nas faces. Foi possível aproximar até $5 \mathrm{~mm}$ da face quente do molde sem ocorrer a fusão. Em alguns pontos mais críticos foram instalados termopares na mesma distância do topo do molde, porém a $6,7 \mathrm{~mm}$ da face quente. Os termopares ficaram mais concentrados na região superior do molde, uma vez que as variações de temperatura são mais significativas nessa região. Com essas informações, foram dispostos os termopares. A instrumentação foi realizada pela empresa siderúrgica vinculada ao projeto. É importante salientar também que os termopares foram divididos por regiões em cada face, separadas da seguinte maneira: centro, extremidade e entre o centro e a extremidade. Essa separação permitiu analisar as regiões mais críticas do molde. A posição dos termopares e as faces do molde estão representadas na figura 2.

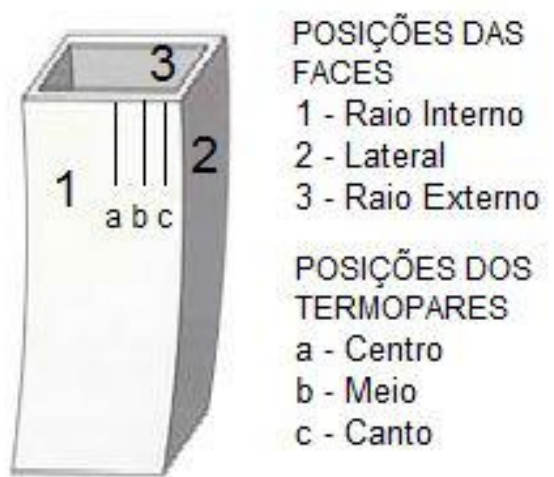

Figura 2. Representação das faces do molde e as posições relativas aos termopares.

\subsection{COMPOSIÇÃO QUÍMICA}

A composição química foi avaliada utilizando-se o carbono equivalente. A equação adotada nesse trabalho para cálculos de Ceq é apresentada na equação 1 [10]. Essa escolha deve-se ao fato da equação ter os mesmos elementos de liga que os aços que serão estudados.

$$
\mathrm{Ceq}=\% \mathrm{C}+0,02 . \% \mathrm{Mn}-0,1 . \% \mathrm{Si}+0,04 . \% \mathrm{Ni}-0,04 . \% \mathrm{Cr}-0,1 . \% \mathrm{Mo}-0,7 \% \mathrm{~S} \text {. }
$$

A composição química é um fator determinante na transferência de calor [1,5,10-12] e sua influência foi avaliada mediante as medições de temperatura nas corridas selecionadas.

\subsection{Corridas Avaliadas}

Foram escolhidas três corridas, com as qualidades SAE 5120, SAE 4340 e SAE 1095. Essas qualidades foram escolhidas devido à variação no carbono equivalente. Seus parâmetros analisados individualmente, visto que, cada qualidade tem sua velocidade e temperatura objetivada, para que a transferência de calor seja otimizada. O aço líquido não pode ultrapassar certa velocidade para evitar problemas como breakout e não deve ter uma baixa velocidade para não ocorrer freezing e reduzir a ocorrência de defeitos superficiais. A temperatura de vazamento

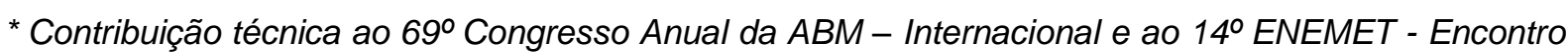
Nacional de Estudantes de Engenharia Metalúrgica, de Materiais e de Minas, 21 a 25 de julho de 2014, São Paulo, SP, Brasil. 


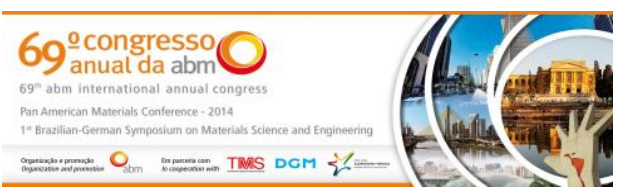

está ligada diretamente à velocidade de lingotamento, ou seja, se o aço líquido não estiver na temperatura objetivada, pode-se alterar a velocidade de lingotamento estabelecida, para que não ocorram os problemas citados anteriormente. A velocidade de lingotamento para as corridas analisadas foi de $1,99 \mathrm{~m} / \mathrm{min}$. As corridas selecionadas para este trabalho estão apresentadas na tabela 1.

Tabela 1. Corridas utilizadas para avaliação do efeito da composição química na transferência de calor

\begin{tabular}{cccc}
\hline Corrida & Qualidade & $\begin{array}{c}\text { T de Vaz. } \\
\left({ }^{\circ} \mathrm{C}\right)\end{array}$ & Ceq \\
\hline 1 & SAE 5120 & 1546 & 0,18 \\
2 & SAE 4340 & 1530 & 0,34 \\
3 & SAE 1095 & 1513 & 0,99 \\
\hline
\end{tabular}

\section{RESULTADOS E DISCUSSÃO}

Os resultados obtidos pelos termopares inseridos correspondem a valores de temperatura ao longo do tempo em função da distância do topo do molde e refletem diretamente na transferência de calor. Os termopares foram identificados com um número, de acordo com sua posição. Os valores de temperaturas são dados industriais sigilosos, este artigo mostrará de maneira comparativa a transferência de calor para diferentes velocidades de lingotamento. As temperaturas observadas nos termopares foram medidas e identificadas como " $x$ ". A partir desse resultado foi

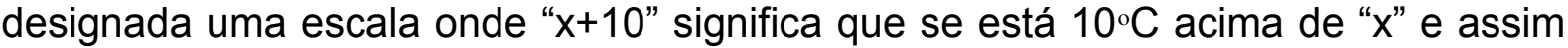
sucessivamente. Ou seja, a variação de temperatura pode ser observada. A figura 3 exemplifica como foram obtidos os dados. Para a avaliação final, foram calculadas as temperaturas médias de cada termopar. Mais detalhes sobre a metodologia e exemplos de valores de temperaturas analisados ao longo do molde, podem ser visualizados no trabalho de Freitas [13].

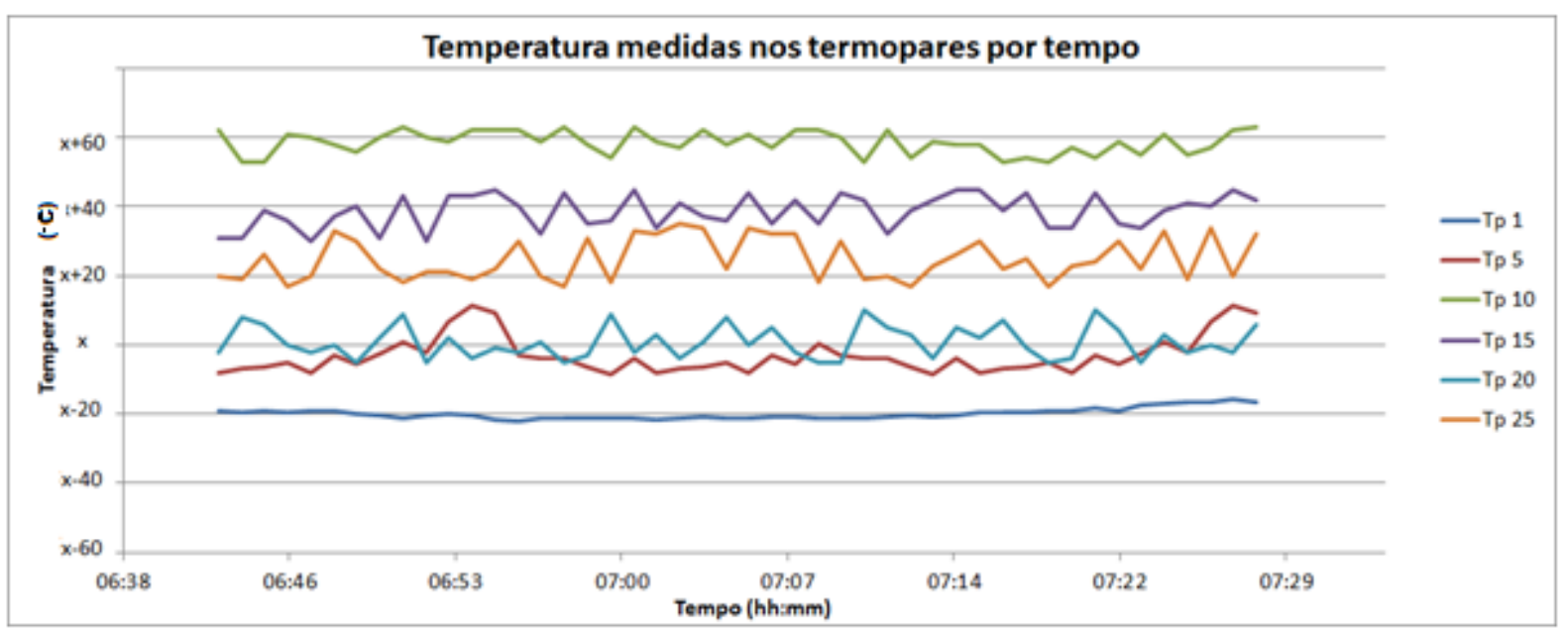

Figura 3. Gráfico temperatura x tempo de termopares no molde no lingotamento de um SAE 1055.

O gráfico da figura 3 exemplifica o comportamento de alguns termopares em função do tempo em uma corrida de um aço SAE 1055. Por estarem posicionados em diferentes pontos do molde, a diferença entre as temperaturas de cada termopar é

* Contribuição técnica ao 69 Congresso Anual da ABM - Internacional e ao 14ํㅡㄹ ENET - Encontro Nacional de Estudantes de Engenharia Metalúrgica, de Materiais e de Minas, 21 a 25 de julho de 2014, São Paulo, SP, Brasil. 


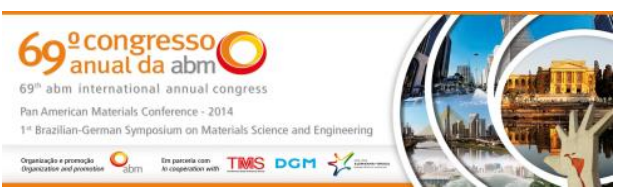

esperada. A média de cada termopar é calculada devido às pequenas variações dentro de cada curva.

A disposição dos termopares resultou em 8 gráficos, 2 para a face lateral, 3 para a face externa e 3 da face interna. As figuras 4 e 5 mostram o estudo da influência do carbono equivalente na transferência de calor, para as faces externa e interna, com termopares dispostos nas extremidades do molde.

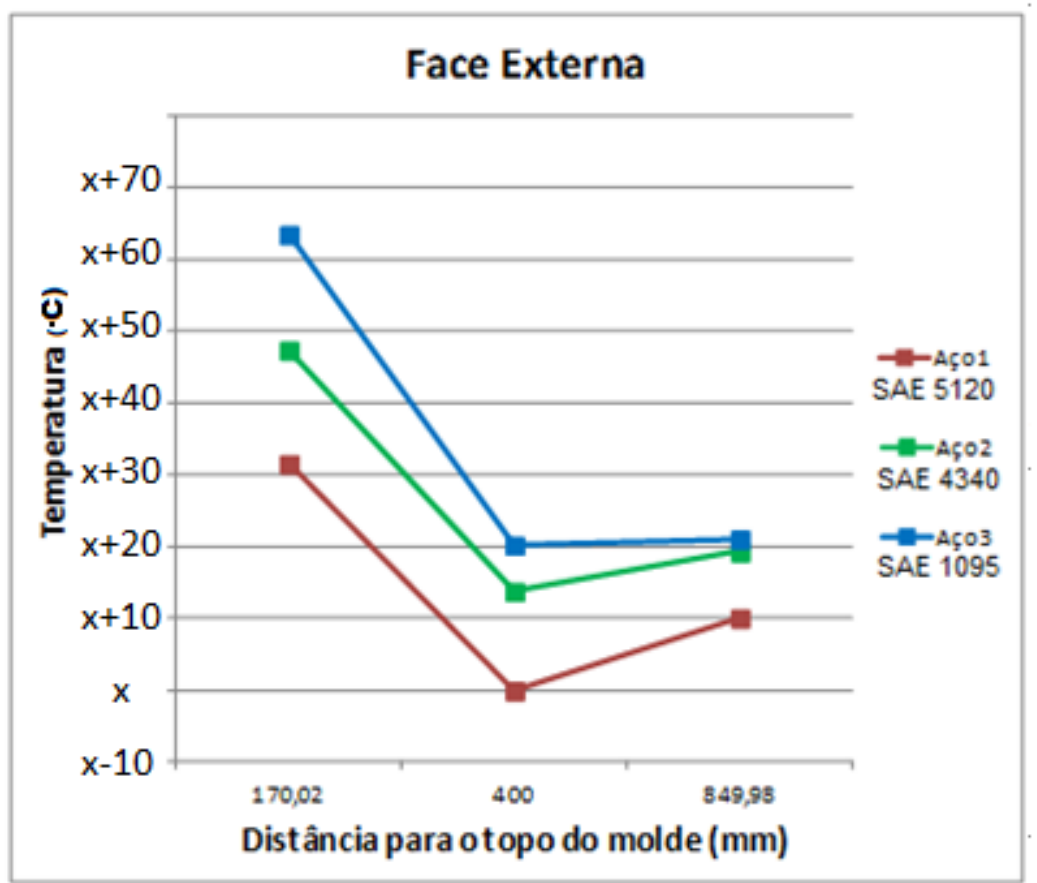

Figura 4. Curvas de Temperatura $x$ Distância do topo do molde, para a face externa com valores medidos na extremidade do molde.

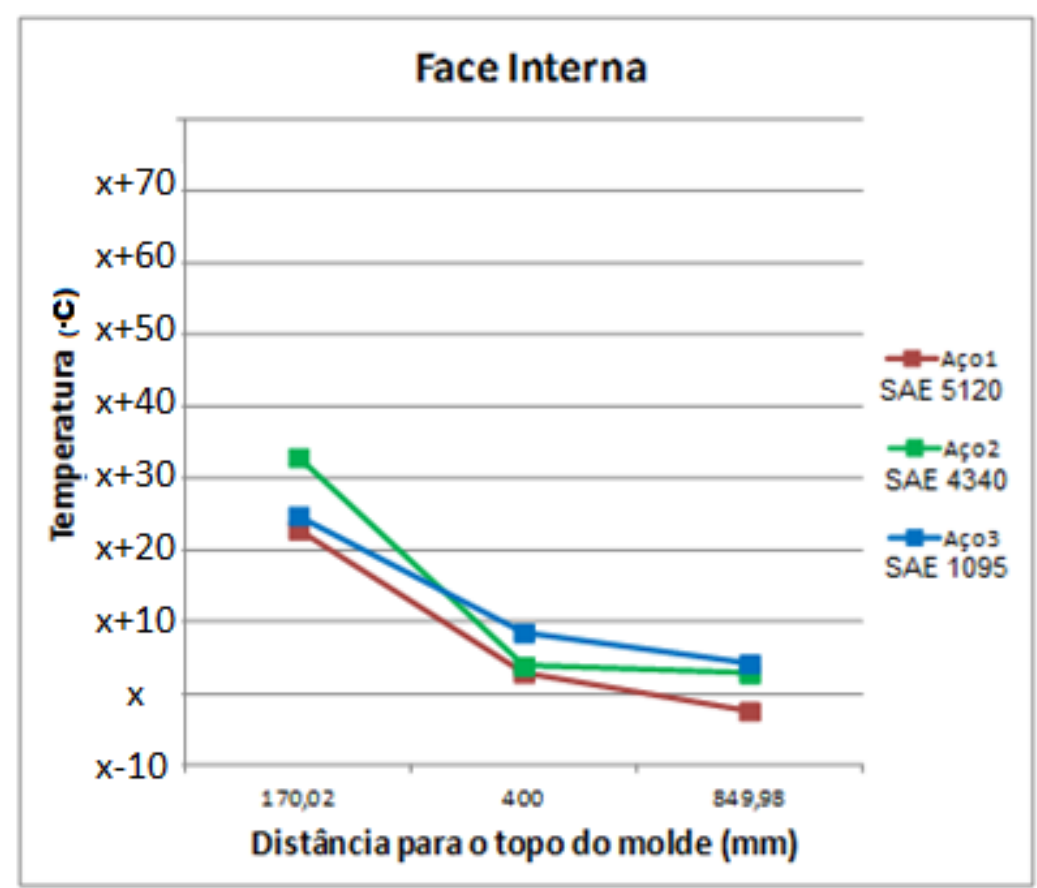

Figura 5. Curvas de Temperatura $x$ Distância do topo do molde, para a face interna com valores medidos na extremidade do molde.

* Contribuição técnica ao 69을 Congresso Anual da ABM - Internacional e ao 14ํㅡㄹ ENEMET - Encontro Nacional de Estudantes de Engenharia Metalúrgica, de Materiais e de Minas, 21 a 25 de julho de 2014, São Paulo, SP, Brasil. 


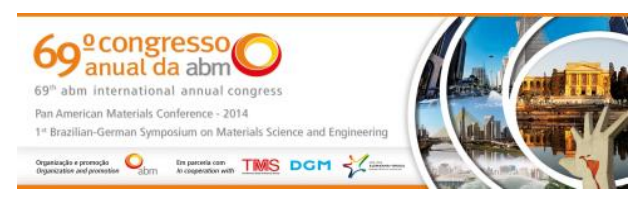

Os termopares dispostos na extremidade do molde (figura 4 e 5) mostram uma grande variação entre a face interna e externa. $O$ aço tem maior contato com a face externa e um maior gap com a face interna, devido à curvatura do molde na máquina de lingotamento e a força da gravidade. Logo, a face externa tem uma tendência maior para a transferência de calor, o que já foi estudado anteriormente em trabalhos da UFRGS [13-14]. Quanto à composição química, é possível notar que quanto maior o carbono equivalente, maior a transferência de calor, o que é condizente com a literatura [5,10-14]. As temperaturas mais altas indicam uma maior transferência de calor para o molde. Nos pontos seguintes, a temperatura é mais baixa, diminuindo a transferência de calor. Entretanto, deve-se levar em conta a contração do aço líquido que está se solidificando. Isso pode ser uma justificativa para a diminuição da transferência de calor.

A figura $6(\mathrm{a} / \mathrm{b} / \mathrm{c})$ mostra os resultados dos termopares localizados entre o centro e a extremidade da face do molde. O comportamento desses termopares difere dos anteriores. Na figura $6 a$, é notado que os aços 2 e 3 têm comportamentos bem semelhantes. Uma explicação para esse comportamento foi estudada por Singh [5], através de análises do fluxo de calor médio no molde em função da porcentagem de carbono, o autor verificou que para aços com teor de carbono de até $0,12 \%$, o fluxo de calor é baixo. Porém, à medida que o teor de carbono se eleva, o fluxo de calor aumenta e torna-se aproximadamente constante para concentrações acima de $0,25 \%$ C. A face lateral, representada pela figura $6 \mathrm{~b}$, mostra uma transferência de calor maior mais significativa para aços com maior percentual de $C$ equivalente. $A$ figura $6 \mathrm{c}$ também tende a ter um comportamento semelhante, o que já havia sido estudado por Barcellos [14].

Já a figura 7 (a/b/c) representa as curvas com termopares localizados no centro da face do molde. Esses evidenciam a região do menisco nos pontos onde existem as maiores temperaturas. Os pontos anteriores ao do menisco estão com temperaturas mais baixas porque não existe aço líquido em contato com o molde nessa região. Os pontos posteriores ao do menisco mostram uma transferência de calor que começa a decair, possivelmente devido ao gap de ar que começa a existir entre o molde e a camada solidificada.

A figura 7a, mostra maior transferência de calor no menisco em comparação com as figuras 7 (b/c). Isso é indicado através das maiores temperaturas dos termopares, podendo ser atribuído à pressão metalostática. Após um pico de alta temperatura, ocorre uma queda acentuada para os aços 2 e 3 a $400 \mathrm{~mm}$ do topo do molde (figura 7a). Isso pode ser caracterizado como uma falha no termopar da face externa. As faces lateral e interna continuam com altas temperaturas, indicando que continua ocorrendo transferência de calor. Para os demais pontos, as temperaturas indicam uma transferência de calor decrescente, o que é previsto pela formação do gap, devido à contração do material, o que está de acordo com o apresentado pelos autores [12-14]. Nos valores medidos no centro do molde, representados na figura 7 (a/b/c), de uma maneira geral, o comportamento dos aços 1, 2 e 3 é semelhante aos das figuras anteriores 4,5 e $6(\mathrm{a} / \mathrm{b} / \mathrm{c})$, onde a transferência de calor é maior para aços com maior teor de carbono equivalente.

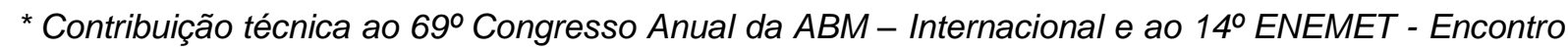
Nacional de Estudantes de Engenharia Metalúrgica, de Materiais e de Minas, 21 a 25 de julho de 2014, São Paulo, SP, Brasil. 


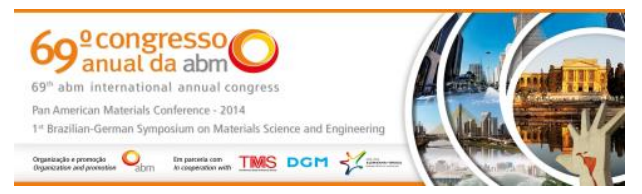

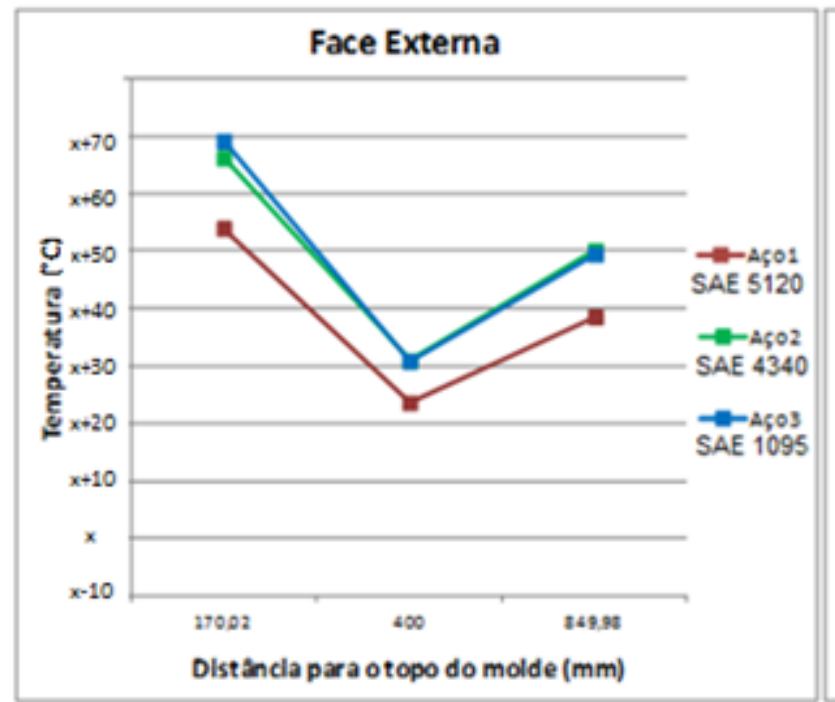

(a)

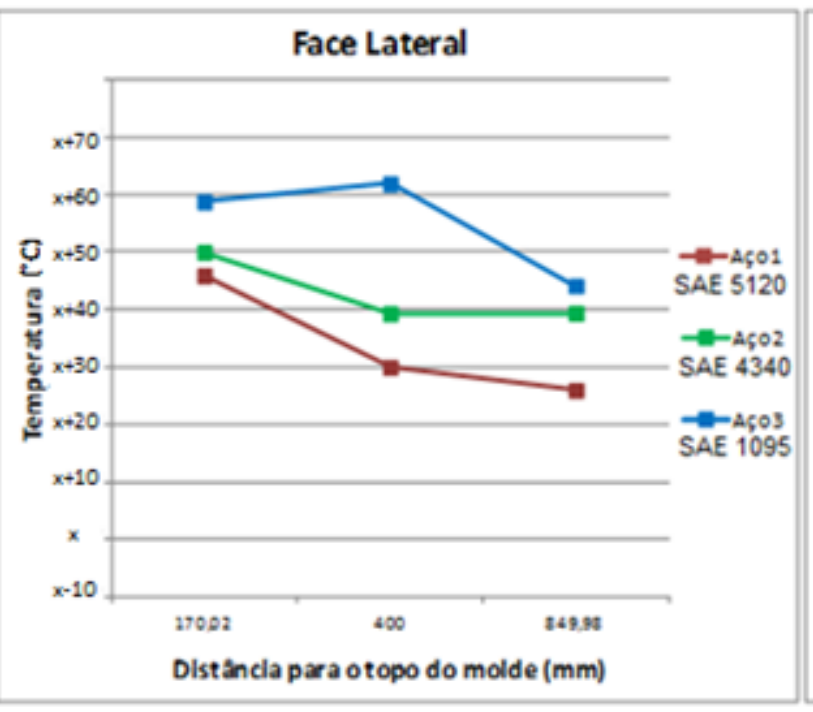

(b)

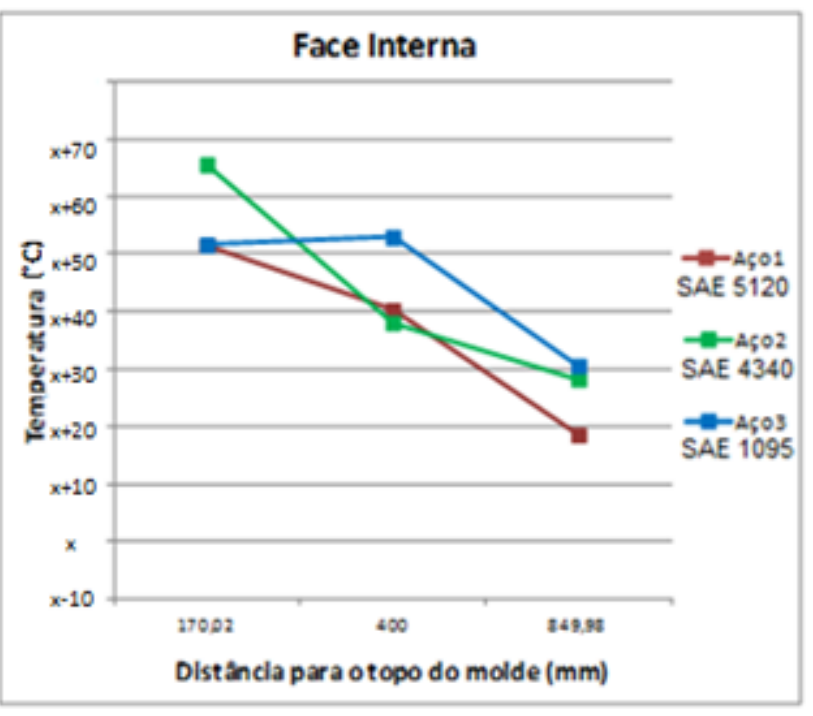

(c)

Figura 6. Curvas de Temperatura x Distância do topo do molde com valores medidos entre a extremidade e o centro do molde. / (a) Face Externa / (b) Face Lateral / (c) Face Interna.

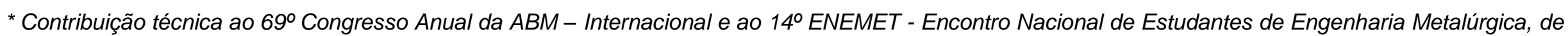
Materiais e de Minas, 21 a 25 de julho de 2014, São Paulo, SP, Brasil. 

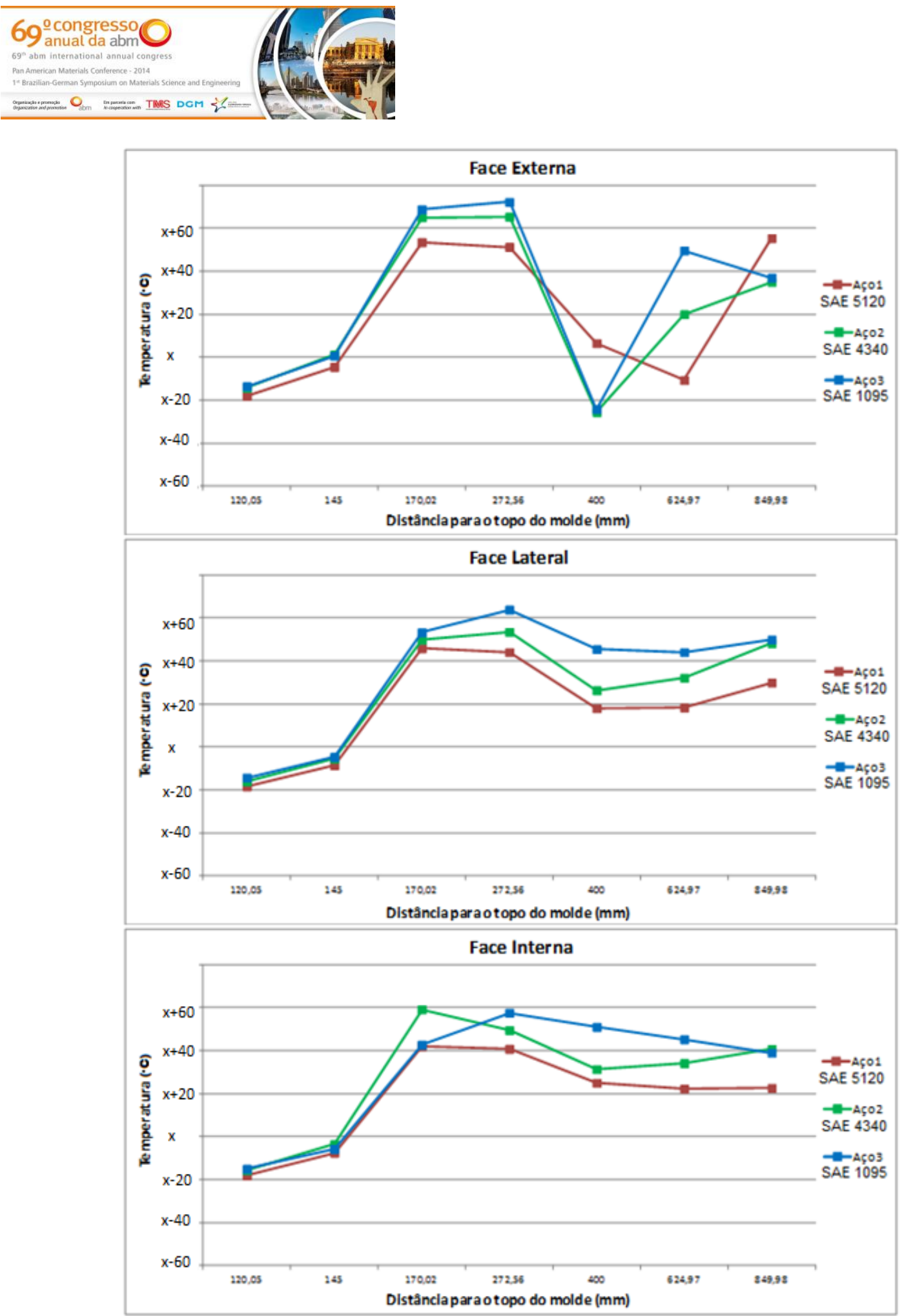

Figura 7. Curvas de Temperatura $x$ Distância do topo do molde com valores medidos no centro do molde./ (a) Face Externa / (b) Face Lateral / (c) Face Interna.

\section{CONCLUSÕES}

- Quanto à posição dos termopares em um molde para tarugos: Os termopares localizados na face externa apresentaram maiores temperaturas, atestando maior transferência de calor do que as demais faces. Quanto à posição dos termopares em cada face, pode-se concluir que a maior transferência de calor ocorre na região central.

- Quanto à composição química do aço: Avaliando-se quanto à composição química dos aços SAE 5120, SAE 4340 e SAE 1095, pode-se concluir que o

* Contribuição técnica ao 69 Congresso Anual da ABM - Internacional e ao 14ํㅡㄹ ENEMET - Encontro Nacional de Estudantes de Engenharia Metalúrgica, de Materiais e de Minas, 21 a 25 de julho de 2014, São Paulo, SP, Brasil. 


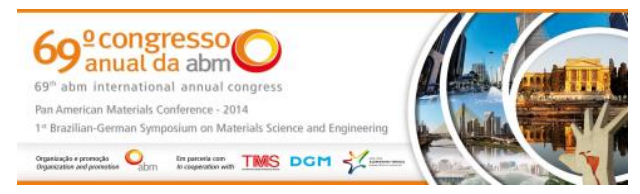

carbono equivalente tem influência direta na transferência de calor. O aumento do carbono equivalente levou a um aumento na transferência de calor. Ou seja, o aço SAE 5120 manteve as menores temperaturas, que iniciaram no menisco e mantiveram-se mais baixas que os aços SAE 4340 e SAE 1095, ao longo do processo. No entanto, nos dois aços avaliados com maior Ceq, a diferença não foi tão expressiva, com as temperaturas próximas na região do menisco para ambos os aços e com tendência a terem a mesma transferência de calor à distância de aproximadamente $850 \mathrm{~mm}$ do topo do molde.

\section{Agradecimentos}

Os autores agradecem o apoio do Professor Jaime Spim (in memoriam), que iniciou esse trabalho. A PROBITI/FAPERGS/UFRGS pelo apoio financeiro. Em especial, ao Engenheiro Ângelo Lançanova Machado pela dedicação e ajuda na elaboração desse artigo.

\section{REFERÊNCIAS}

1 Kulkarni MS, Babu S. Managing quality in continuous casting process using product quality model and simulated annealing. Journal of Materials Processing Technology. 2005;166:294-306.

2 Araújo ES, Gasparini VM, Silva CA, Silva IA, Carvalho HC, Mansur F, Perim CA, Seshadri $V$. Comportamento do aço líquido na região do menisco do molde de lingotamento contínuo via modelagens física e matemática. Tecnologia em Metalúrgica, Materiais e Mineração. 2010;7(1-2):18-23.

3 Vynnycky M. On the role of radiative heat transfer in air gaps in vertical continuous casting. Applied Mathematical Modelling. 2011;37:2178-2188.

4 Garcia A, Spim, JA, Santos CA, Cheung N. Lingotamento Contínuo de Aços. Associação Brasileira de Metalurgia e Materiais. 2006;1:320.

5 Singh SN, Blazek KE. Heat transfer and skin formation in a continuous casting mould as a function of steel carbon content. Journal of metals. 1974;26:17-27.

6 Lotov AV, Kamenev GK, Berezkin VE, Miettinen K. Optimal control of cooling process in continuous casting of steel using a visualization-based multi-criteria approach. Applied Mathematical Modelling. 2005;29(7):653-672.

7 Furtmuller C, Colaneri P, Del RL. Adaptive robust stabilization of continuous casting. Automatica. 2012;48:225-232.

8 Incropera F. Fundamentos de Transferência de Calor e de Massa. Campinas: Ltc; 2008.

9 Garcia A. Solidificação: Fundamentos e Aplicações. Campinas: UNICAMP; 2001.

10 Wolf MM, Kurz W. The effect of carbon content on solidification of steel in the continuous casting mold. Metallurgical Transactions B. 2001;12B:85-93.

11 Ho K, Pehlke RD. Mechanisms of heat transfer at a metal-mold interface. AFS Transactions. 1984;92:587-598.

12 Harste K, Schwerdtfeger K. Shrinkage of round iron carbon ingots during solidification and subsequent cooling. ISIJ International. 2003;43(7):1011-1020.

13 Freitas BB. Análise da influência de parâmetros de lingotamento na transferência de calor durante a solidificação de aços especiais [trabalho de conclusão de curso]. Porto Alegre: Universidade Federal do Rio Grande do Sul; 2013.

14 Barcellos VK. Análise da transferência de calor durante a solidificação de aços em moldes de lingotamento contínuo [tese de mestrado]. Porto Alegre: Universidade Federal do Rio Grande do Sul; 2007.

\footnotetext{
* Contribuição técnica ao 69ำ Congresso Anual da ABM - Internacional e ao 14ํㅡㄹ ENEMET - Encontro Nacional de Estudantes de Engenharia Metalúrgica, de Materiais e de Minas, 21 a 25 de julho de 2014, São Paulo, SP, Brasil.
} 